\title{
Análise de indicadores higiênico-sanitários no leite bovino cru refrigerado comercializado na microrregião de Ji-Paraná - Rondônia - Brasil
}

\author{
Analysis of hygienic-sanitary indicators in chilled raw bovine millk marketed in the microregion of \\ Ji-Paraná - Rondônia - Brazil \\ Análisis de indicadores higiénico-sanitarios en leche cruda bovina refrigerada comercializada en la \\ microrregión de Ji-Paraná - Rondônia - Brasil
}

\section{Resumo}

O objetivo do estudo foi analisar os parâmetros higiênico-sanitários do leite bovino cru refrigerado sob o Sistema de Inspeção Federal (SIF), comercializado na microrregião de Ji-Paraná - RO, Brasil. A pesquisa foi realizada com 600 amostras coletadas ao longo de 90 dias provenientes de propriedades rurais produtoras de leite bovino. Foi realizada a contagem de células somáticas (CCS) e a contagem total de bactérias (CTB) em laboratório. Os dados foram analisados e classificados pelo padrão de qualidade referente as instruções normativas $n^{\circ} 76$ e 77 do Ministério da Agricultura Pecuária e Abastecimento (MAPA), foi realizado o estudo de proporção de amostra única $(\alpha=0,05)$ pelo software Action 
Stat ${ }^{\circledR}$ 3.7. Com base nos resultados evidenciou-se que 52\% (312/600) das amostras apresentaram CBT em conformidade com a legislação, assim como, para o teste de CCS, 85,2\% (511/600). E, ao analisar os indicadores higiênico-sanitários do leite, a média da CTB variou de $600.000 \mathrm{UFC} / \mathrm{mL}$ a $860.000 \mathrm{UFC} / \mathrm{mL}$, enquanto a CCS oscilou de $320.000 \mathrm{CCS} / \mathrm{mL}$ a $350.000 \mathrm{CCS} / \mathrm{mL}$. As amostras analisadas apresentaram média trimestral superior ao preconizado pela IN $n^{\circ} 76$, não sendo assim aprovado para CTB. No entanto, com relação a avaliação de CCS, observa-se que o grupo amostral se encontra em conformidade com que se recomenda. Há necessidade de aperfeiçoamento das boas práticas de higiene ao longo de todo o processo de obtenção e manutenção do leite cru refrigerado, visando melhorar a qualidade do leite bovino comercializado na região, e consequentemente atender os requisitos estabelecidos na legislação federal.

Palavras-chave: CTB; CTS; Padrão de qualidade; Qualidade do leite; Saúde pública.

\begin{abstract}
The aimed of the study was to analyze the hygienic-sanitary parameters of chilled raw bovine milk under the Federal Inspection System (SIF), commercialized d in the microregion of Ji-Paraná - RO, Brazil. The study was carried out with 600 samples collected over 90 days from rural properties producing bovine milk. The somatic cell count (CCS) and total bacterial count (CTB) were performed in the laboratory. The data were analyzed and classified by the quality standard referring to the normative instructions $\mathrm{n}^{\circ} 76$ and 77 of the Ministry of Agriculture, Livestock and Supply (MAPA), the study of proportion of single sample $(\alpha=0.05)$ was carried out by the Action Stat ${ }^{\circledR}$ software 3.7. Based on the results, it was evidenced that 52\% (312/600) of the samples presented CBT in compliance with the legislation, as well as, for the CCS test, $85.2 \%$ (511/600). And, when analyzing the hygienic-sanitary indicators of milk, the CTB average ranged from $600,000 \mathrm{CFU} / \mathrm{mL}$ to $860,000 \mathrm{CFU} / \mathrm{mL}$, while the CCS fluctuated from $320,000 \mathrm{CCS} / \mathrm{mL}$ to $350,000 \mathrm{CCS} / \mathrm{mL}$. The analyzed samples showed a quarterly average higher than that recommended by $\mathrm{IN} \mathrm{n}^{\circ} 76$, thus not being approved for CTB. However, regarding the CCS assessment, it is observed that the sample group is in accordance with what is recommended. There is a need to improve good hygiene practices throughout the process of obtaining and maintaining chilled raw milk, with a view to improving the quality of bovine milk sold in the region, and consequently meeting the requirements established by federal legislation.
\end{abstract}

Keywords: CTB; CTS; Milk quality; Public health; Quality standard.

\title{
Resumen
}

El objetivo del estudio fue analizar los parámetros higiénico-sanitarios de la leche cruda bovina refrigerada bajo el Sistema de Inspección Federal (SIF), comercializada en la microrregión de Ji-Paraná - RO, Brasil. La investigación se llevó a cabo con 600 muestras recolectadas durante 90 días de propiedades rurales productoras de leche bovina. El recuento de células somáticas (CCS) y el recuento bacteriano total (CTB) se realizaron en el laboratorio. Los datos fueron analizados y clasificados por el estándar de calidad haciendo referencia a las instrucciones normativas $\mathrm{n}^{\mathrm{o}} 76 \mathrm{y}$ 77 del Ministerio de Agricultura, Ganadería y Abastecimiento (MAPA), el estudio de proporción de muestra única $(\alpha=0,05)$ fue realizado por la Acción Software Stat ${ }^{\circledR}$ 3.7. Con base en los resultados, se evidenció que el 52\% (312/600) de las muestras presentaron CBT en cumplimiento de la legislación, así como, para la prueba CCS, el 85,2\% (511/600). $\mathrm{Y}$, al analizar los indicadores higiénico-sanitarios de la leche, el promedio de CTB osciló entre $600.000 \mathrm{UFC} / \mathrm{mL}$ a $860.000 \mathrm{UFC} / \mathrm{mL}$, mientras que el CCS fluctuó de $320.000 \mathrm{CCS} / \mathrm{mL}$ a $350.000 \mathrm{CCS} / \mathrm{mL}$. Las muestras analizadas presentaron un promedio trimestral superior al recomendado por la IN $\mathrm{n}^{\mathrm{o}} 76$, por lo que no fueron aprobadas para CTB. Sin embargo, con respecto a la evaluación de la CCS, se observa que el grupo de muestra está de acuerdo con lo recomendado. Es necesario mejorar las buenas prácticas de higiene en todo el proceso de obtención y mantenimiento de la leche cruda refrigerada, con miras a mejorar la calidad de la leche bovina que se comercializa en la región y, en consecuencia, cumplir con los requisitos establecidos por la legislación federal.

Palabras clave: Calidad de la leche; Calidad estandar; CTB; CTS; Salud pública.

\section{Introdução}

Entende-se por leite, sem outra especificação, o produto oriundo da ordenha completa, ininterrupta, em condições de higiene, de vacas sadias, bem alimentadas e descansadas (Brasil, 2018). O leite é um dos produtos mais completos da alimentação humana (Gracindo \& Pereira, 2009; Mörschbächer et al., 2018). Entretanto, por ser rico em nutrientes favorece a proliferação de microrganismos deteriorantes e patogênicos, os quais representam um risco à saúde da população (Santos et al., 2015; Gasparotto et al., 2020).

O Brasil detém o maior rebanho bovino comercial do mundo, com aproximadamente 215 milhões de cabeças (Batista, 2020) e a nível nacional o estado de Rondônia é o $8^{\circ}$ maior produtor de leite e o maior da região Norte (Idaron, 2019; Morais et al., 2020) com pecuária leiteira, em geral de base familiar, com destaque na economia regional (Embrapa, 2019; Ribeiro et al., 
2020). Ao utilizar o leite com finalidades comerciais e alimentícias, é primordial a aplicação de medidas de controle de qualidade (Almeida Junior \& Ozelin, 2017).

Assim, os laticínios passaram a bonificar os produtores pela qualidade do leite, buscando baixos níveis de contagem bacteriana total (CBT), contagem de células somáticas (CCS) e altos teores de gordura e proteína, pois políticas de premiação por qualidade podem contribuir para a melhora da qualidade do leite (Nightingale et al., 2008; Morais et al., 2020). Adicionalmente, os consumidores exigem cada vez mais alimentos saudáveis (Mörschbächer et al., 2018), e na busca pela segurança alimentar, padronização e melhoria na qualidade, torna-se necessário uma atenção elevada dos produtores, das indústrias e principalmente dos órgãos governamentais responsáveis pela fiscalização (Gasparotto et al., 2020).

Diante dos pressupostos apresentados, objetivou-se analisar os parâmetros higiênico-sanitários do leite bovino cru refrigerado sob o Sistema de Inspeção Federal (SIF), comercializado na microrregião de Ji-Paraná, no estado de Rondônia, Brasil.

\section{Metodologia}

Esse artigo de pesquisa é derivado de um trabalho de conclusão de curso intitulado "Análise de indicadores higiênicosanitários no leite cru refrigerado na região central do estado de Rondônia” (Santana, 2020).

\subsection{Localização e Amostragem}

O estudo é caracterizado como experimental por meio do teste de variáveis relacionadas a qualidade higiênico-sanitária do leite comercializado na microrregião de Ji-Paraná - RO (Pereira et al., 2018). Para isso, a pesquisa foi realizada com 600 amostras coletadas ao longo de 90 dias provenientes de propriedades rurais produtoras de leite bovino situadas na microrregião de Ji-Paraná, no estado de Rondônia, Brasil. Os animais estudados foram da raça girolando, criadas sob sistema de pastejo onde o objetivo do estudo foi o leite oriundo destes animais.

\subsection{Coleta e Processamento das amostras}

As amostras foram coletadas de maneira asséptica, obedecendo o critério de boas práticas de coleta de leite preconizado pela Rede Brasileira de Laboratórios de Qualidade do Leite, para isso a coleta foi feita em tanques resfriadores dentro da temperatura preconizada pela legislação, por esse motivo é dispensado a aprovação no conselho de ética no uso de animais, sendo coletada por um profissional habilitado e treinado, onde se usa o material estéril. Seguidamente se realiza a agitação do leite por 5 minutos, e logo após se procede com a coleta nos coletores especiais para contagem de células somáticas (CCS) e contagem total de bactérias (CTB) (Santana, 2020). As amostras foram armazenadas em caixas isotérmicas com gelo seco e enviadas para o Laboratório de qualidade do leite da Associação Paranaense de Criadores de Bovinos da Raça Holandesa (APCBRH), onde as análises foram realizadas pelo método de citometria de fluxo para CCS e CTB e infravermelho para composição através dos equipamentos Bentley Sistema Combinado 2300 e Bentley Bactocount IBC respectivamente. (Santana, 2020).

\subsection{Análise Estatística}

Os dados foram analisados pelo programa Excel® 2013 e para classificação do padrão de qualidade referente as instruções normativas n 76 e 77 do Ministério da Agricultura Pecuária e Abastecimento (MAPA) de 2018, foi realizado o estudo de proporção de amostra única pelo software Action Stat ${ }^{\circledR}$ 3.7, como base estatística para calcular a porcentagem de amostras que estavam de acordo com os parâmetros estabelecidos pela legislação, a nível de 5\% de probabilidade. 


\section{Resultados}

Com base nos resultados evidenciou-se que 52\% (312/600) das amostras analisadas apresentaram CBT em conformidade com os padrões da legislação vigente, assim como para o teste de CCS, 85,2\% (511/600) das amostras estavam em conformidade com a legislação (Figura 1).

Figura 1 - Contagem bacteriana total (CTB) (A) e contagem das células somáticas (CCS) (B) presentes no leite bovino cru refrigerado e comercializado na microrregião de Ji-Paraná - Rondônia, ao longo de 90 dias.

(A)

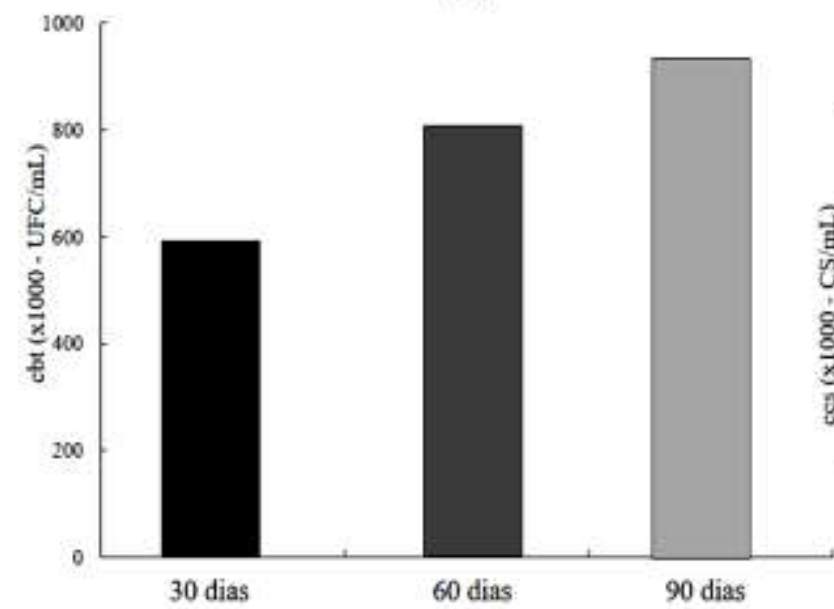

(B)

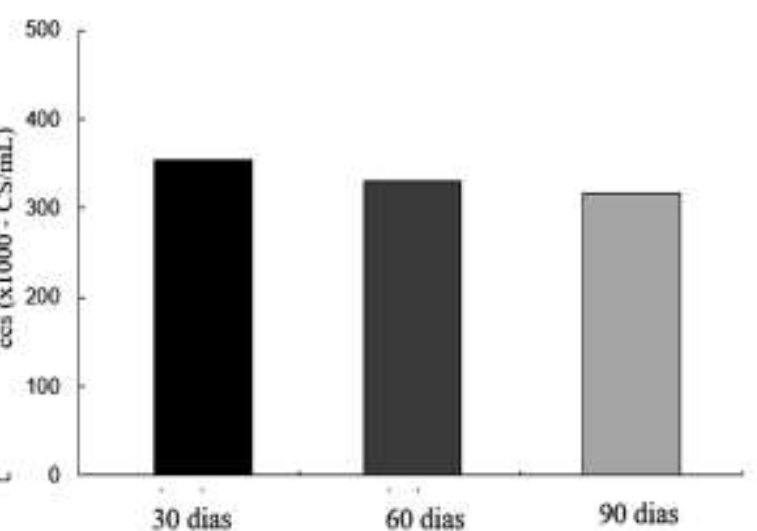

Fonte: Arquivo dos autores.

E, ao analisar os indicadores higiênico-sanitários do leite, a média da contagem bacteriana total variou de 600.000 UFC/mL a $860.000 \mathrm{UFC} / \mathrm{mL}$ (Figura 2A), enquanto a de células somáticas oscilou de $320.000 \mathrm{CCS} / \mathrm{mL}$ a $350.000 \mathrm{CCS} / \mathrm{mL}$ (Figura 2 B). Na Figura 3 pode-se visualizar a análise comparativa das amostras analisadas frente aos padrões da IN $n^{\circ} 76$, tanto para CBT como para CCS. A IN no 76 determina que o resultado de CBT na análise do leite para ser aprovado no critério qualidade, não deve ultrapassar a média geométrica trimestral de $300.000 \mathrm{UFC} / \mathrm{mL}$ e ser inferior a $500.000 \mathrm{CCS} / \mathrm{mL}$ para ser aprovado na análise de CCS (Figura 4). Desse modo, as amostras analisadas no grupo amostral apresentaram média trimestral superior ao preconizado pela IN $n^{\circ} 76$, não sendo assim aprovado no que diz respeito a variável referente a CTB presentes no leite. No entanto, com relação a avaliação de CCS, observa-se que o grupo amostral se encontra em conformidade com que se recomenda a $\mathrm{IN}^{\circ}{ }^{\circ} 76$, visto que estão aproximadamente $200.000 \mathrm{CCS} / \mathrm{mL}$ abaixo do limite máximo permitido. 


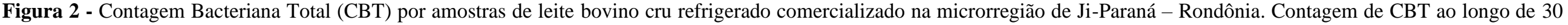
dias (A), Contagem de CBT ao longo de 60 dias (B) e Contagem de CBT ao longo de 90 dias.

(A)

30 dias

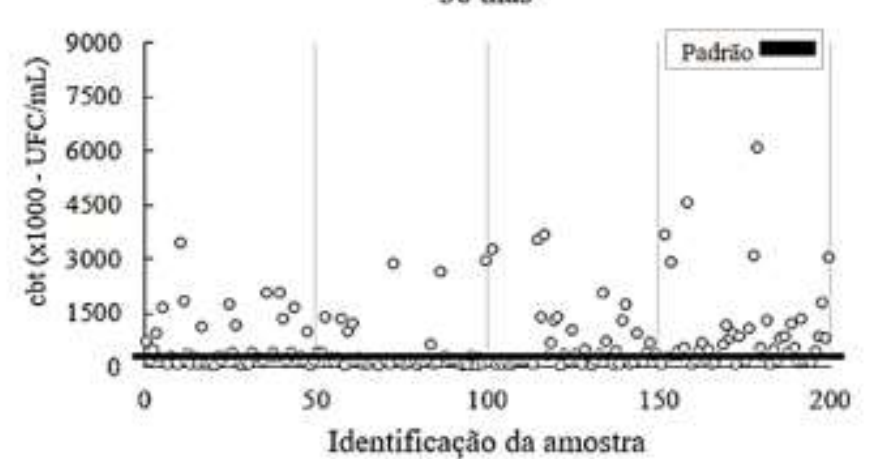

(B)

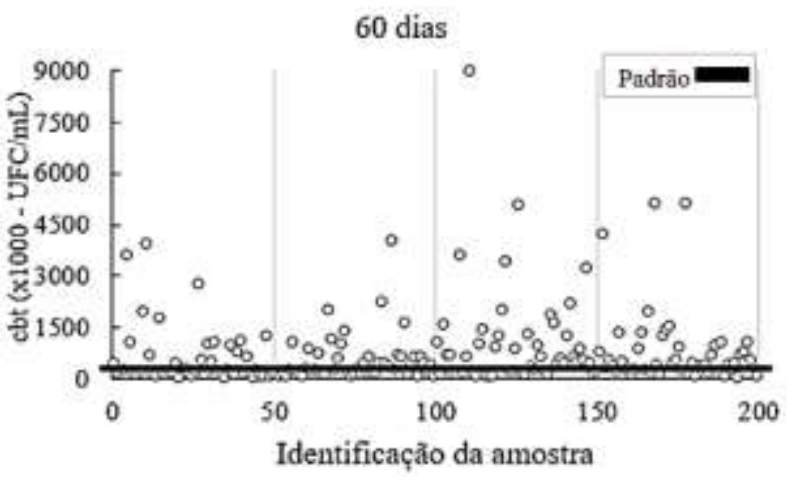

(C)

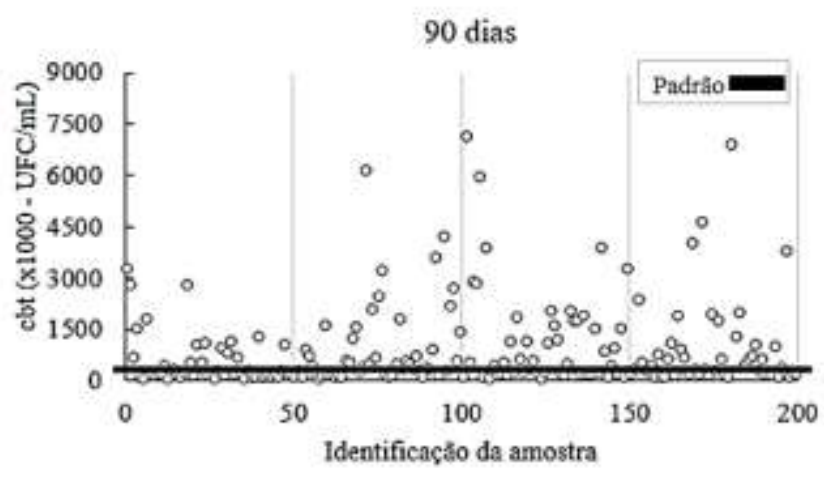

Fonte: Arquivo dos autores. 


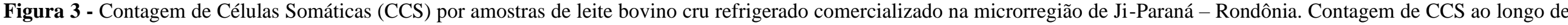
30 dias (A), Contagem de CCS ao longo de 60 dias (B) e Contagem de CCS ao longo de 90 dias.

(A)

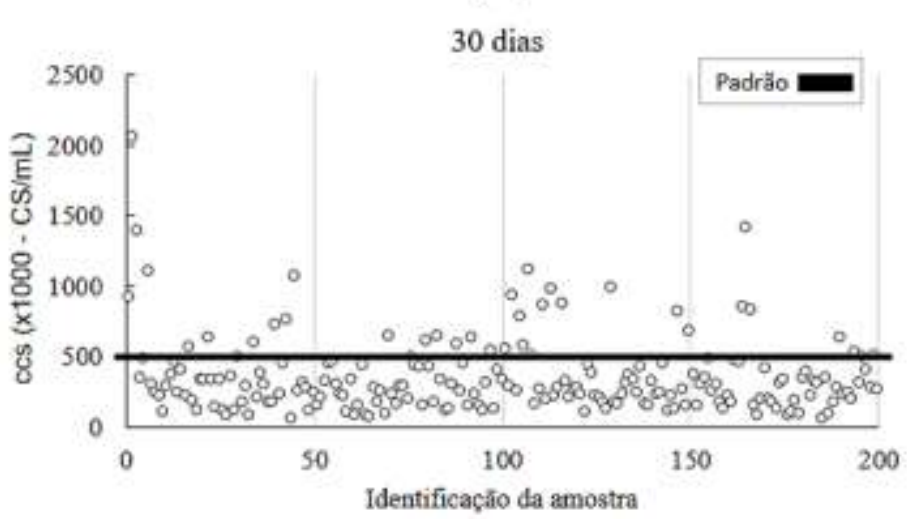

(B)

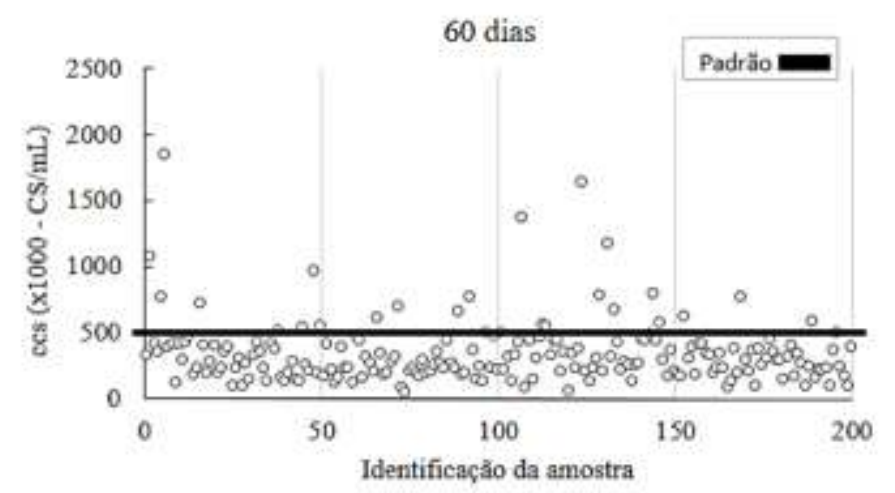

(C)

90 dias

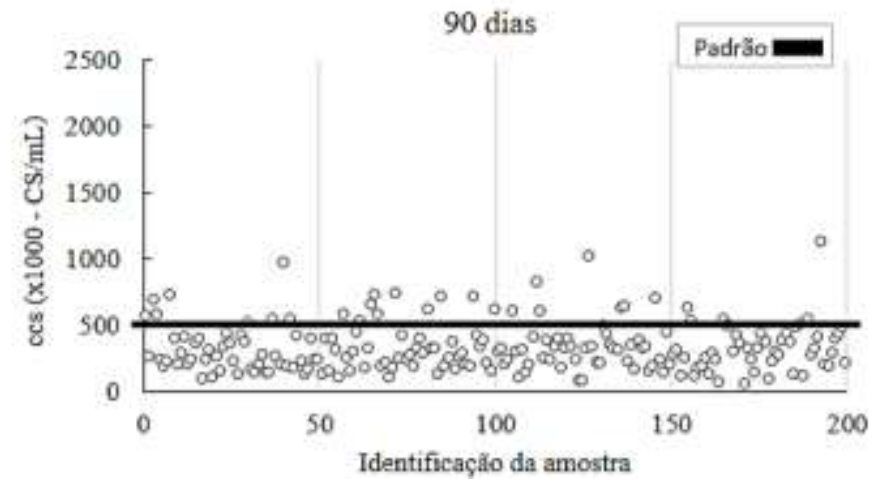

Fonte: Arquivo dos autores. 


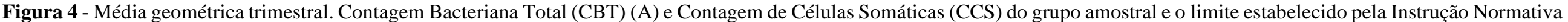
$\mathrm{n}^{\mathrm{o}} 76(\mathrm{~B})$.

(A)

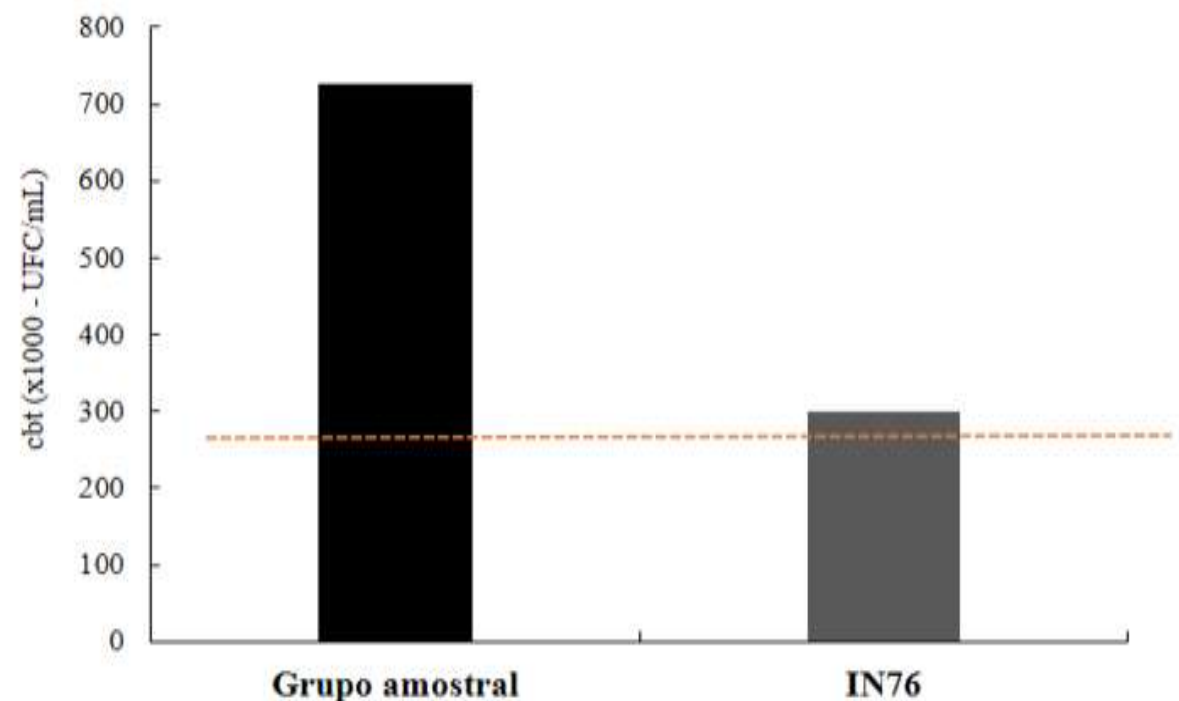

(B)

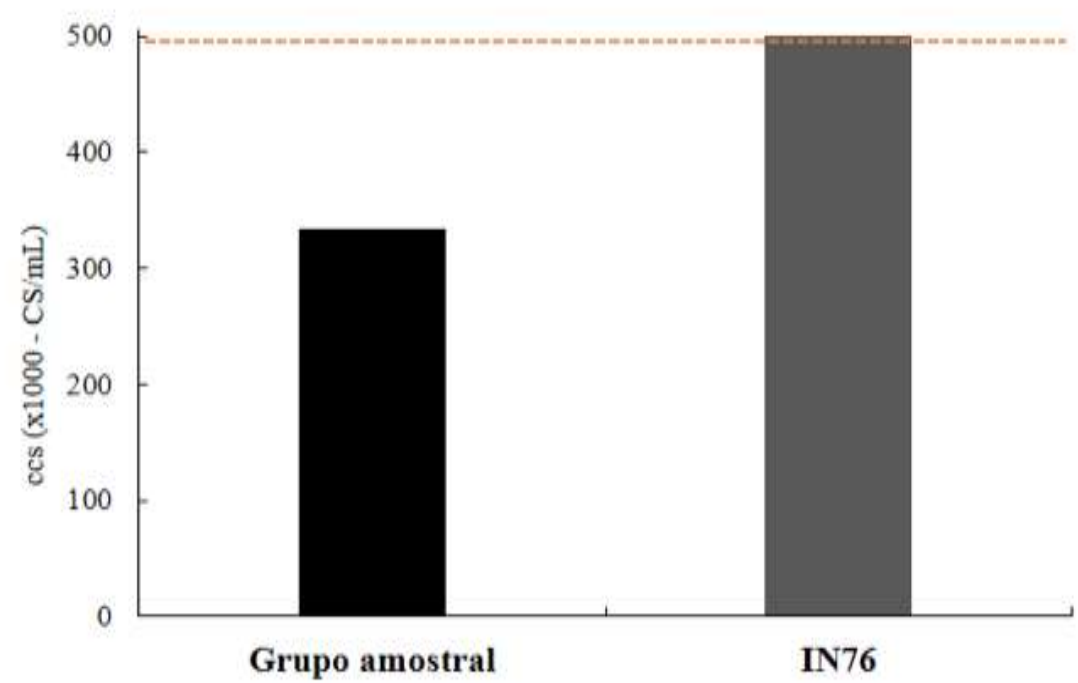

Fonte: Arquivo dos autores 


\section{Discussão}

A CBT é um parâmetro de grande valia na indicação do nível de higiene e de cuidados aplicados na obtenção do leite (Eckstein et al., 2014). Desse modo, o presente estudo demonstrou que as amostras analisadas não atingiram o perfil satisfatório preconizado pela $\mathrm{IN} \mathrm{n}^{\circ} 76$, possivelmente em função de falhas em procedimentos de limpeza dos equipamentos, transporte do leite, armazenamento e/ou refrigeração. Elevando assim, o número de bactérias presentes no leite analisado. Em estudos em propriedades leiteiras na região Sudeste do Brasil foi evidenciado que em geral, ocorre a realização de procedimentos inadequados de higienização das salas de ordenha, utensílios e equipamentos, ou até mesmo tais práticas acabam sendo ignoradas, e consequentemente não realizadas (Brito et al., 2004; Almeida et al., 2016), fato ocorrente em outras regiões brasileiras e nos mais distintos sistemas produtivos.

Adicionalmente, a CBT elevada nessa pesquisa pode estar relacionada ao fato de ter sido mensurada em amostras coletadas no período chuvoso no estado de Rondônia (Almeida, 2011; Franca, 2015). Há relatos que demonstram que as médias de CBT são maiores no período chuvoso do que no período seco, vindo a apresentar uma diferença aproximada de 94.000 UFC/mL entre os períodos (Bueno et al., 2008; Carvalho \& Souza, 2013). Em geral, o período das chuvas favorece o aumento da contaminação ambiental, o acúmulo de lama nas instalações e maior ocorrência de tetos sujos no momento da ordenha (Bueno et al., 2008). Esses fatores, associados às falhas na rotina de ordenha, podem ter causado uma elevada contaminação inicial.

Todavia, práticas simples como uso de água em temperatura elevada associada com detergente alcalino clorado na limpeza de equipamentos e troca de borrachas e mangueira semestralmente propiciam decréscimos no CBT (Cordioli \& Oldra, 2009). Além disso, o processo de refrigeração do leite cru é de extrema importância para evitar a multiplicação bacteriana e consequentemente preservar sua qualidade o armazenando a uma temperatura de $4^{\circ} \mathrm{C}$ (Almeida et al., 2006; Dias et al., 2015). Tais práticas são passíveis de serem adotadas nos mais distintos sistemas produtivos, inclusive nos empreendimentos leiteiros do estado de Rondônia, onde os rebanhos são caracterizados por baixo padrão tecnológico com animais pouco especializados e adoção predominantemente de ordenha manual uma vez ao dia (Dias et al., 2016; Gasparotto et al., 2020).

No presente estudo evidenciou-se que na microrregião de Ji-Paraná as propriedades distribuem-se pelos municípios de Ji-Paraná, Governador Jorge Teixeira, Jaru, Mirante da Serra, Nova União, Ouro Preto do Oeste, Presidente Médici, Teixeiropólis, Theobroma, Urupá e Vale do Paraíso. Alguns trabalhos na literatura relatam que o uso de ordenha mecânica pode estar envolvidocom o aumento de novas infecções da glândula mamária por causa de sua má utilização, principalmente na transmissão de patógenos de uma vaca para outra, contaminação cruzada no copo coletor, falhas na pulsação, queda de teteiras, introdução de ar no sistema de ordenha e ocorrência de traumas nos tetos (Philpote \& Nickerson, 2002; Langoni et al., 2011).

No entanto, pelo fato da produção leiteira de Rondônia se caracterizar por baixo padrão tecnológico, sugere-se que os baixos níveis de CCS encontrados neste trabalho podem estar relacionados a essa baixa tecnificação das propriedades da região. Todavia, os valores de CCS foram similares ao relatados em fazendas leiteiras da região do Triângulo Mineiro (Barbosa et a., 2009), a qual é o tipo de ordenha mais usual nas fazendas produtoras de leite em Rondônia (Dias et al., 2016). Enquanto isso, na região do Vale do Taquari-RS os resultados mostraram índices de células somáticas entre 500.000-878.000 CS/mL (Conti, 2016), valores esses superiores aos encontrados na presente pesquisa e ao recomendado pela IN $\mathrm{n}^{\circ} 76$.

Sabendo que o CCS é importante para avaliar o manejo sanitário do rebanho produtor do leite (Eckstein et al., 2014), essa informação positiva alcançada com relação ao grupo amostral analisado, é consequentemente, uma importante variável de qualidade a ser relatada e exposta à população consumidora do leite da região de Rondônia (Farias et al., 2018). Grande parte do leite produzido em Rondônia é originada de pequenos produtores (Gasparotto et al., 2020). Devido ao baixo volume de produção, a aquisição de tanques de expansão para resfriamento do leite se torna onerosa. Dessa forma, alguns autores acreditam que o volume de leite produzido pode ser correlacionado com a qualidade final do leite (Reis et al., 2020). 
No caso específico dos produtores de Rondônia que não possuem tanques resfriadores, poderiam até fazer uso dos tanques coletivos, porém alguns têm acesso limitado devido as más condições de estradas na região amazônica. Mas, é válido salientar que somente o fato de manter o leite em tanques resfriadores não garante qualidade do mesmo, assim, a prática de prevenção e controle de mastite no rebanho juntamente com adoção de boas práticas de higienização são de suma importância para diminuir os prejuízos e melhorar a qualidade do leite (Morais et al., 2020).

Contudo, considerando que o limite padrão estabelecido pela legislação brasileira não é tão rígida quanto de países como Estados Unidos, países membros da União Europeia, Nova Zelândia e Austrália, e ainda assim, alguns laticínios não são aprovados na avaliação de qualidade do leite, esse fator distancia o Brasil da liderança na exportação de produtos lácteos (Vargas et al., 2013). Desse modo, há necessidade de intensificar a fiscalização nas propriedades, oferecer conhecimentos por meio de programas de extensão, assistência técnica no manejo do rebanho e incentivos para produção. E, em Rondônia, há ainda a necessidade de fiscalização mais minuciosa quanto ao manejo da ordenha e do processamento do leite, com a finalidade de fornecer um leite de melhor qualidade a população (Santos et al., 2017).

\section{Conclusão}

O leite bovino cru refrigerado comercializado na microrregião de Ji-Paraná, no estado de Rondônia, apresenta CCS em conformidade com a legislação vigente, enquanto a CBT ficou acima dos valores de referência para um leite de boa qualidade. Desse modo, há a necessidade de aperfeiçoamento das boas práticas de higiene ao longo de todo o processo de obtenção e manutenção do leite cru refrigerado, bem como bonificações ativas de pagamento por qualidade e atividade de políticas públicas, visando estimular a produção leiteira e melhorar a qualidade do leite bovino comercializado na região, e consequentemente, atender os requisitos estabelecidos na legislação federal. Para continuidade do trabalho, sugere-se realizar um estudo dos indicadores higiênico-sanitários em toda a bacia leiteira do estado de Rondônia.

\section{Referências}

Almeida, A. C., Santos, C. A. A., Menezes, I. R., Teixeira, L. M., Costa J. P. R., \& Souza R. R. (2017). Perfil sanitário de unidades agrícolas familiares produtoras de leite cru refrigerado e adequação à legislação vigente. Ciência Animal Brasileira, 17, 303-315. 10.1590/1089-6891v17i314597

Almeida, G. M. (2010). Qualidade microbiológica do leite cru refrigerado, no município de Ouro Preto do Oeste - Rondônia - Brasil. Tese de Doutorado em Ciências da Saúde, Universidade de Brasília, Brasília - DF.

Almeida Junior B. M. S., \& Ozelin C. B. S. (2017). Fundamentos de controle de qualidade na produção, beneficiamento e industrialização do leite bovino. Revista Investigação, 16(8), 76-81. 10.26843/investigacao.v16i8.1833

Aragão, J. L. (2017). Avaliação da pecuária leiteira de Rondônia pelo índice global de sustentabilidade. Tese de Doutorado em Desenvolvimento Regional e Meio Ambiente, Universidade Federal de Rondônia, Porto Velho - RO.

Asselt, V. E. D., Fels-Klerx, V. H. J. P., Bokhorst, V. V. V. H., \& Groot M. N. (2016). Overview of Food Safety Hazards in the European Dairy Supply Chain. Comprehensive Reviews in Food Science and Food Safety, 16(1), 59-75, 2016. 10.1111/1541-4337.12245

Barbosa, C. P., Benedetti, E., \& Guimarães, E. C. (2009). Incidence of mastitis in cows subjected to different types of milking on dairy farms in the Triângulo Mineiro region. Bioscience Journal, 25(6), 121-128.

Batista, E. L. S., Soares Filho, B. S., Rajão, R. G., Barbosa, F. A., \& Costa, M. A. (2020). Cenários para intensificação da bovinocultura de corte brasileira: Ed. IGC/UFMG.

Ministério da Agricultura, Pecuária e Abastecimento. Instrução Normativa $\mathrm{n}^{\circ} 76$, de 26 de novembro de 2018. Regulamentos técnicos que fixam a identidade e as características de qualidade que devem apresentar o leite cru refrigerado, o leite pasteurizado e o leite pasteurizado tipo A. Diário Oficial da União: Brasília.

Brito, J. R., Brito, M. A. V. P., Pinto, S. M., Souza, G. N., Arcuri, E. F., Brito, M. A. V. P., \& Silva, M. R. (2004). Adoção de boas práticas agropecuárias em propriedades leiteiras da Região Sudeste do Brasil como um passo para a produção de leite seguro. Acta Scientiae Veterinariae, 32(2), 125-131. 10.22456/16799216.16834

Bueno, V. F. F., Mesquita, A. J., Nicolau, E. S., Oliveira, A. N., Oliveira, J. P., Nevesm R. B. S., Mansur, J. R. G. \& Thomaz, L. W. (2008). Contagem células somáticas: relação com a composição centesimal do leite e período do ano no estado de Goiás. Ciência Rural, 32(4), 848-854, 2008. 10.1590/S010384782005000400016

Carvalho, G. L. O., \& Souza, G. N. (2013). Uso da análise espacial para avaliação de indicadores de qualidade do leite na microrregião de Ji-Paraná, Rondônia. Revista do Instituto de Laticínios Cândido Tostes, 68(390). 10.5935/2238-6416.20130011 
Carvalho, G. L. O., Silva, J. A., Oliveira E. F., Junior J. E. F., Faria, C. G., Vicentini, N. M., \& Souza, G. N. (2009). Avaliação dos componentes do leite e contagem de células somáticas de rebanhos bovinos localizados na microrregião de Ji-Paraná, Rondônia. EMATER. Porto Velho/RO, 2009.

Conti, R. M. (2016). A influência da contagem de células somáticas do leite cru no rendimento da produção de queijo prato (lanche), junto ao laticínio Sgorla situado na região do Vale do Taquari-RS. Monografia apresentada ao curso de Química Industrial, Universidade do Vale do Taquari, Lajeado - RS.

Cordioli, E., \& Oldra, A. (2009). Sistemas de produção de leite e qualidade do produto final na agricultura familiar. Cadernos de Agroecologia, 4(1).

Dias, J. A., \& Antes, F. G. (2014). Qualidade físico-química, higiênico-sanitária e composicional do leite cru: Indicadores e aplicações práticas da Instrução Normativa 62. (1ª . ed.): EMBRAPA Rondônia.

Dias, J. N., Fontinele, L. L., Machado, S. M. O., Oliveira, J. S., Ferreira, G. P., \& Pereira, A. C. T. C. (2015). Avaliação das Condições Higiênico-Sanitárias de Leite Cru e Queijo Coalho Comercializados em Mercados Públicos no Norte do Piauí. Revista Saúde e Pesquisa, 8(2). 10.17765/2176-9206.2015v8n2p277-284

Dias, J. A., Souza, M. G., Grego, C. R., \& Mendes A. M. (2016). Boletim de Pesquisa e Desenvolvimento: Impacto da iniciativa de pagamento por qualidade do leite sobre indicadores higiênico-sanitários de tanques de resfriamento de leite: Embrapa Rondônia.

EMBRAPA. (2019). Empresa Brasileira de Pesquisa Agropecuária. Gado do Leite. Pesquisa aponta desafios e soluções para a qualidade do leite de agroindústrias em Rondônia.

Farias, T. G. S., Rocha, I. V., Ferraz, P. M., \& Jácome-Junior, T. A. (2018). Avaliação de indicadores higiênico-sanitários em leite in natura comercializado em Caruaru, Brasil. Archivos de Zootecnia, 67(259): 10.21071/az.v67i259.3795

Eickstein, I. I., Pozza, M. S. S., Zambom, M. A., Ramos, C. E. C. O., Tsutsumi, C. Y., Fernandes, T., \& Busanello M. (2014). Qualidade do leite e sua correlação com técnicas de manejo de ordenha. Scientia Agraria Paranaensis, 13(2), 143-151, 2014: 10.18188/sap.v13i2.7071

Franca, R. R. (2015). Climatologia das chuvas em Rondônia - período 1981-2011. Revista de Geografias, 11(1).

Gasparotto, P. H. G., Daudt, C., Silva, F. R. C., Dantas Filho, J. V., Marchi, P. G., Souza, F. A., Gujanswski, C. A., \& Rodrigues, D. S. (2020). Analyzes of alizarol, acidity and formaldehyde of UTH milk commercialized in the municipality of Ji-Paraná - Rondônia. Journal of Veterinary Science and Public Health, $7(2), 84-96$

Gracindo, A. P. A. C., \& Pereira G. F. (2009). Produzindo leite de alta qualidade: Empresa de Pesquisa Agropecuária do RN (EMPARN).

IDARON. (2019). Agência de Defesa Sanitária Agrosilvopastorial do estado de Rondônia. Relatório da produção de leite com base nos dados referentes a 46 etapaf. aftosa (abril e maio de 2019).

Langoni, H., Penacchio, D. S., Citadella, J. C. C., Laurino, F., Faccioli-Martins, P. Y., Lucheis, S. B., Menozzi, B. D., \& Silva A. V. (2011). Quality and microbiological aspects of bovine milk. Pesquisa Veterinária Brasileira, 31(12): 10.1590/S0100-736X2011001200004

Menezes, M. F. C., Simeoni, C. P., Etchepare, M. A., Huerta, K., Bortoluzzi, D. P., \& Menexes C. R. (2014). Microbiota e conservação do leite. Revista Eletrônica em Gestão, Educação e Tecnologia Ambiental, 18, 76-89: 10.5902/2236117013033

Morais, S. B., Orlandi, C. M. B., Gasparotto, P. H. G., Dantas Filho, J. V., Cavali, J., Campeiro Junior, L. D., \& Daudt, C. (2020). Custos e Benefícios da Inseminação Artificial em Pequenas Propriedades Leiteiras. Revista Agrarian, 13(48), 249-264: 10.30612/agrarian.v13i48.10652

Mörschbächer, V., Rempel, C., \& Maciel, M. (2018). Microbiological quality of refrigerated raw milk in the dairy farm and after transport to the processing dairy plant. Arquivos do Instituto Biológico, 84, 2018:10.1590/1808-1657000422016

Nightingale, C., Dhuyvetter, K., Mitchell, R. \& Schukken, Y. (2008). Influence of Variable Milk Quality Premiums on Observed Milk Quality. Journal of Dairy Science, 91(3), 1236-1244: 10.3168/jds.2007-0609

Nunes, G. F. M., De-Paula, A. V., \& Castro, H. F. (2010). Modificação bioquímica da gordura do leite. Revista Química Nova, $33(2), 431-437$.

Paes-de-Souza, M., Amin, M. M. \& Gomes, S. T. (2009). Agronegócio leite: características da cadeia produtiva do estado de Rondônia. Revista de Administração e Negócios da Amazônia, 1(1).

Pereira, S. A., Shitsuka, D. M., Parreira, F. J., \& Shitsuka, R. (2018). Metodologia da pesquisa científica. UFSM, NTE.

Philpot, W. N., \& Nickerson, S. C. (2002). Vencendo a Luta Contra a Mastite: WestfaliaLandtechnik do Brasil.

Reis, E. M. B., Vieira, J. A., Lopes, M. A., Demeu, F. A., Bruhn, F. R. P., Vicente, F. H., Pereira, A. B., \& Simões Filho L. M. (2020). Diagnóstico de propriedades leiteiras e fatores associados à qualidade higiênico-sanitária do leite. Publicações em Medicina Veterinária, 4(2): 10.31533/pubvet.v14n2a508.1-15

Ribeiro, A. A., Oliveira, A. V. D., Reis, E. M. B., \& Dantas Filho, J. V. (2020). Uso de ferramentas de gestão na pecuária leiteira: um estudo de caso em Sena Madureira, Acre, Brasil. Tekhne e Logos, 11(1).

Santana, A. S. (2020). Análise de indicadores higiênico-sanitários no leite cru refrigerado refrigerado na região central do estado de Rondônia. Monografia apresentado ao curso de Medicina Veterinária, Centro Universitário São Lucas, Ji-Paraná - RO.

Santos, J. F., Dutra, B. F., Colaço Filho, M. A. C., Barros, R. B., Rolim, M. B. Q., \& Franque M. P. (2015). Qualidade microbiológica do leite cru refrigerado e da água utilizada em propriedades leiteiras da microrregião de Guaranhuns-PE. Acta Veterinária Brasilica, 9(1), 71-76: 10.21708/avb.2015.9.1.5214

Santos, D. G., Queite, H., Gazola, G. B., Silva, O. B., \& Matos N. (2017). Análise microbiológica de leite produzido em Rondônia e comercializado no município de Porto Velho-RO. South American Journal of Basic Education, Technical and Technological, 4(1), 79-89. 
Research, Society and Development, v. 10, n. 2, e49210211999, 2021

(CC BY 4.0) | ISSN 2525-3409 | DOI: http://dx.doi.org/10.33448/rsd-v10i2.11999

SEBRAE. (2015). Serviço de apoio às micro e pequenas Empresas em Rondônia. Diagnóstico do agronegócio do Leite e Derivados do estado de Rondônia. Porto Velho.

Vargas, D. P., Nornberg, J. L., Oliveira, M. R., Sheibler, R. B., Milani, M. P., \& Mello F. C. B. (2013). Correlações entre contagem bacteriana total e parâmetros de qualidade do leite. Revista Brasileira de Ciência Veterinária, 20(4). 10.4322/rbcv.2014.009

Wentz, A. G., Bermudes, R. F., Martins, C. M. M., Osmari, M. P., Rodrigues, B. M., \& Pozza, M. S. S. (2018). Different methods and times of milk conservation: physical-chemical composition and microbiological quality. Acta Veterinária Brasilica, 12(3), 84-93: 10.21708/avb.2018.12.3.7698 